\title{
Effectiveness and Tolerability of Ivabradine with or Without Concomitant Beta-Blocker Therapy in Patients with Chronic Stable Angina in Routine Clinical Practice
}

Stefan Perings · Georg Stöckl • Malte Kelm •

On behalf of the RESPONSIfVE study investigators

Received: May 26, 2016 / Published online: July 18, 2016

(c) The Author(s) 2016. This article is published with open access at Springerlink.com

\section{ABSTRACT}

Introduction: In the prospective, open-label, non-interventional, multicenter $\mathrm{RESPONSI}_{\mathrm{f}} \mathrm{VE}$ study, the effectiveness, response rates and tolerability of ivabradine with or without beta blocker (BB) were evaluated in patients with chronic stable angina pectoris (AP) in daily clinical practice.

Methods: In patients with AP, ivabradine was given twice daily in flexible doses for 4 months. Resting heart rate (HR), number of angina attacks, short-acting nitrate use, severity of symptoms [by Canadian Cardiovascular Society (CCS) score] and tolerability with or without existing BB therapy were documented

Enhanced content To view enhanced content for this article go to http://www.medengine.com/Redeem/90E4 F060015D0F89.

S. Perings $(\bowtie)$

CardioCentrum Düsseldorf, Düsseldorf, Germany

e-mail: stefan.perings@t-online.de

G. Stöckl

Department of Medical Affairs, Servier Deutschland

$\mathrm{GmbH}$, Munich, Germany

M. Kelm

Department of Cardiology, Pneumology und

Angiology, University Medical Center Düsseldorf,

Düsseldorf, Germany and analyzed using descriptive statistical methods.

Results: In total, 1250 patients with AP (mean age $\quad 66.0 \pm 10.9$ years, $\quad 59.6 \%$ male, $31.9 \%$ previous myocardial infarction) and an indication for ivabradine were included. Sixty-five percent of all patients received BB. Further concomitant standard medication included aspirin (74.2\%), statins (69.3\%), angiotensin-converting enzyme inhibitors/ angiotensin receptor blockers (84.2\%), diuretics (40.0\%), long-acting nitrates (15.7\%), and calcium antagonists (21.4\%). After 4 months of ivabradine treatment (mean daily dose $11.0 \pm 2.7 \mathrm{mg}$ ), mean $\mathrm{HR}$ was reduced from $82.4 \pm 11.8$ beats per minute (bpm) to $67.1 \pm 8.4 \mathrm{bpm}$. The average number of angina attacks/week decreased from $1.2 \pm 1.9$ to $0.1 \pm 0.6$ and the average use of short-acting nitrates/week from $1.5 \pm 2.8$ units to $0.2 \pm 1.0$ units. CCS classification of patients improved from $76 \%$ classified in CCS grades II or III and $24 \%$ in CCS grade I to $66 \%$ classified in CCS grade I and only 35\% remaining in CCS grades II or III at study end. Response rate to ivabradine (defined as $\mathrm{HR}<70 \mathrm{bpm}$ or $\mathrm{HR}$ reduction $\geq 10 \mathrm{bpm}$ ) $\quad$ reached $\quad 87 \%$. HR 
reduction, symptomatic improvement and response rates were comparable in patients with or without BB. Adverse drug reactions were reported for $2.2 \%$ of patients.

Conclusion: In this prospective study over a four-month period in clinical practice, ivabradine effectively reduced $\mathrm{HR}$, angina attacks, and nitrate consumption in patients with AP with or without concomitant BB therapy. Ivabradine improved CCS scores and achieved a high treatment response rate with good general tolerability.

\section{Funding: Servier.}

Trial registration: Controlled-trials.com identifier, ISRCTN73861224.

Keywords: Angina attacks; Beta blocker; Cardiology; CCS grade; Heart rate reduction; Ivabradine; Nitrate consumption; Stable angina pectoris; Symptom improvement

\section{INTRODUCTION}

High heart rate (HR) induces myocardial ischemia and thereby triggers symptoms of angina pectoris (AP) in the presence of coronary stenoses [1-3]. Elevated HR is also associated with increased cardiovascular and total mortality in patients with coronary artery disease (CAD), after myocardial infarction (MI), with chronic heart failure (CHF), and also in the general population without obvious cardiovascular disease [4-9]. Reducing HR has therefore become an important therapeutic strategy in the treatment of patients with cardiovascular disease, also being reflected in international guidelines [10-12].

While HR reduction with beta blockers, which are most commonly used for that purpose, or ivabradine, which is selectively blocking the "funny" current $\left(I_{\mathrm{f}}\right)$ channel in the pacemaker cells of the sinoatrial node [13], have both been shown to improve cardiovascular mortality and morbidity in patients with CHF [12], rather mixed results were found in patients with stable CAD. According to a couple of new analyses, an improvement of prognosis with beta blocker in stable CAD seems to be strictly restricted to a population with recent MI [14-16]. On the other hand, a subgroup analysis of the BEAUTIFUL trial (ClinicalTrials.gov identifier: NCT00143507) revealed that ivabradine in addition to beta blocker and other guideline recommended therapies improved coronary outcomes in patients with CAD with left ventricular (LV) systolic dysfunction and limiting AP [17, 18], while neutral results were obtained for ivabradine in the recent SIGNIFY trial (ClinicalTrials.gov identifier: NCT02446990) in patients with stable CAD with preserved LV function and no signs of heart failure [19]. In SIGNIFY, a small but statistically significant increase in the occurrence of the primary endpoint was seen for ivabradine compared to placebo in the subgroup of patients with limiting angina [Canadian Cardiovascular Society $(\mathrm{CCS}) \geq 2$ ]. However, it should be noted that considerably higher ivabradine doses than currently approved by health authorities have been used in that trial.

Given the very low mortality rates with contemporary guideline recommended medications in stable CAD $[19,20]$, the main focus of therapy shifts to improvement of residual angina symptoms, exercise capacity and therefore quality of life (QoL) in these patients. To achieve these goals, recent guidelines for the treatment of stable $\mathrm{CAD}$ recommend reducing the resting $\mathrm{HR}$ of patients with CAD to between 55 and 60 beats per minute (bpm) [10, 11]. In clinical practice, HR reduction with beta blocker alone is not always 
sufficient and many patients remain symptomatic [21, 22]. In addition, due to their broad mode of action and resulting side effects, up-titration of beta blockers often remains a difficult barrier in daily routine [21]. Current European Society of Cardiology (ESC) guidelines recommend ivabradine not only as an alternative anti-anginal agent to beta blockers, but especially emphasize the role of combining beta blockers and ivabradine for more effectively reducing HR and improving AP symptoms [11].

The efficacy and safety of ivabradine in symptomatic AP therapy has been shown in controlled trials without concomitant beta-blocker use [23, 24]. Moreover, the ASSOCIATE study (ClinicalTrials.gov identifier: NCT00202566) including over 800 patients with stable AP, proved that combining ivabradine and beta blocker was effective and safe under controlled conditions [25]. This was also demonstrated in the setting of everyday clinical practice by two large observational studies in patients with and without beta-blocker treatment [26-28], resulting in reduction of angina attacks and need for short-acting nitrates. CCS class distribution and QoL also improved, accompanied by good general tolerability.

We designed the RESPONSI $\mathrm{fE}$ (Evaluation of effectiveness and therapeutic response to ivabradine in daily practical use for chronic stable angina patients) study to further assess the symptomatic effectiveness, treatment response, and tolerability of ivabradine in one large cohort of patients with stable AP with and without existing beta-blocker therapy in daily clinical practice.

\section{METHODS}

Patients with stable AP requiring further anti-anginal treatment and fulfilling criteria for ivabradine therapy according to the approved indication and ESC guideline recommendations [11] were included in this non-interventional study by general practitioners and internists in an outpatient setting. In detail these were symptomatic patients with coronary heart disease and normal sinus rhythmus, who were either unable to tolerate or had a contraindication to beta blockers, or were not adequately controlled with an optimal (meaning maximally tolerated) beta-blocker dose ( $\mathrm{HR}>60 \mathrm{bpm}$ at the time of the study). Symptomatic patients with and without concomitant beta-blocker therapy could therefore be included into the study. Exclusion criteria were defined by explicit contraindications for ivabradine treatment according to approved drug label. There were three scheduled visits, one at baseline (visit 1), a control visit after 4 weeks (visit 2), and the final examination after 4 months (visit 3). All data was documented using a standardized case report form (CRF).

The procedures followed were in accordance with the ethical standards of the responsible committee on human experimentation (institutional and national) and with the Helsinki Declaration of 1975 , as revised in 2000 and 2008. Informed consent was obtained from all patients for being included in the study. Ethical approval was granted by the independent ethics commission in Freiburg/ Germany (FEKI). This trial is registered at controlled-trials.com with registration number ISRCTN73861224. Demographic and disease-specific medical history data, information about concomitant diseases, other medical therapies and reasons for initiating ivabradine treatment were recorded at baseline visit. Patients were treated with ivabradine in flexible doses over a 4-month period. The recommended starting dose was $5 \mathrm{mg}$ twice daily $(2.5 \mathrm{mg}$ twice daily in elderly patients 
aged $\geq 75$ years). If necessary, the dose could be adjusted at visit 2 to a maximal dose of $7.5 \mathrm{mg}$ twice daily or a lower dose of $2.5 \mathrm{mg}$ twice daily in case of pronounced HR reduction $<50 \mathrm{bpm}$.

Stable AP was clinically documented at each visit by recording HR, weekly angina symptoms, weekly nitrate use, and CCS class. Other cardiac parameters assessed at baseline and/or during the course of the study were, e.g., NYHA class, LV dysfunction (LVD), history of MI, revascularization therapies like percutaneous coronary intervention (PCI) or coronary artery bypass grafting (CABG), and blood pressure. At visit 3 , all changes in concomitant medications were evaluated. To assess the overall response rate of patients to ivabradine, treatment response was defined as achieving a $\mathrm{HR}<70 \mathrm{bpm}$ and/or an absolute HR reduction of $\geq 10 \mathrm{bpm}$ at study end (visit 3 ). In addition, a final evaluation of the overall effectiveness and tolerability of ivabradine therapy was made using a physician's assessment scale with categories "very good", "good", "moderate", and "poor".

The main focus of this study was to evaluate the symptomatic outcome of ivabradine-treated patients with and without concomitant beta-blocker therapy. For assessment of beta-blocker treatment status, patients were further divided into three subgroups according to the beta-blocker dose at baseline as a percentage $(<50 \%, 50-99 \%, \geq 100 \%)$ of the defined maximal doses. Additional subgroups were specified according to gender, age $(</ \geq 75$ years $)$, resting $\mathrm{HR}(</ \geq 75 \mathrm{bpm})$, CCS class (I-IV), patients with or without MI, PCI or LVD, and patients on monotherapy or add-on treatment with ivabradine at baseline. All adverse drug reactions (ADR) occurring during the study period had to be documented and assessed by the physician on a specific ADR reporting form at each patient visit. ADR were coded in accordance with the Medical Dictionary for Regulatory Activities (MedDRA) version 17.0.

A strictly descriptive statistical analysis of the results was performed due to the non-interventional design of the study. Data are presented as mean values \pm standard deviations (SD) for continuous variables and numbers of patients and/or percentages for categorical variables. Analysis of effectiveness data was performed with data imputation according to the last value carried forward (LVCF) method. Wilcoxon's signed-rank test and Chi-square test were applied for assessment of changes between baseline and follow-up visits. Corresponding $P$ values should be interpreted descriptively. All study data were evaluated by an independent statistical institute (ANFOMED GmbH, Möhrendorf, Germany). All statistical analyses have been performed by means of the $\mathrm{SAS}^{\circledR}$ software system (version 9.4 for Microsoft Windows $7^{\mathrm{TM}}$; SAS Institute Inc., Cary, NC, USA).

\section{RESULTS}

\section{Baseline}

A total of 1250 patients with chronic stable AP (intention to treat population) were enrolled in this non-interventional study in 338 centers in Germany. Data of 1247 patients (99.8\%) were available for all three visits. The mean study duration was 4.05 months. The mean age of the cohort was $66.0 \pm 10.9$ years $(22.9 \% \geq 75$ years $)$, $59.6 \%$ of the patients were male. $31.9 \%$ of the total study cohort had a history of MI, $46.8 \%$ and $11.1 \%$ underwent PCI or CABG, respectively. $34.5 \%$ of patients had LVD, mean LV ejection fraction (LVEF) was $47.0 \% \pm 11.9 \%$. Conduction disorders were present in $18.1 \%$ of patients. Atrial 
fibrillation, mainly paroxysmal, was diagnosed in $11.9 \%$ of the study population. The most common concomitant diseases/risk factors were arterial hypertension (84.2\%), dyslipidemia (62.2\%), obesity (41.3\%), smoking (34.5\%), and diabetes (33.2\%). Cardiovascular medication at baseline consisted of, e.g., Aspirin (74.2\%), statins (69.3\%), angiotensin-converting enzyme inhibitors/angiotensin receptor blockers $(84.2 \%)$, diuretics $(40.0 \%)$, calcium antagonists (21.4\%), and long-acting nitrates (15.7\%; see Table 1 for subgroup data).

$64.7 \%$ of all patients received beta blockers. $17.9 \%$ of those patients received $\geq 100 \%$ of the defined maximal dose, $55.6 \%$ between $50 \%$ and $99 \%$ of the maximal dose, and $26.5 \%$ less than $50 \%$ of the maximal dose (Table 2 ).

Ivabradine was selected as initial therapy in $34.6 \%$ of patients and in $49.6 \%$ as additional therapy. $15.8 \%$ of patients switched to ivabradine, most frequently from beta blocker, and often due to intolerance/side effects $(58.9 \%)$ or insufficient efficacy $(50.0 \%)$. At study entry and last visit, mean daily dose of ivabradine was $9.7 \pm 1.8$ and $11.0 \pm 2.7 \mathrm{mg}$, respectively. Initially, $86.8 \%$ of patients received $2 \times 5 \mathrm{mg}$ ivabradine per day. In $62.6 \%$ of patients, the initial dose remained constant during the study, while it was escalated to the targeted maintenance dose of $2 \times 7.5 \mathrm{mg}$ per day in $22.8 \%$ of the patients.

\section{Treatment Effects of Ivabradine}

At baseline, mean HR was $82.4 \pm 11.8 \mathrm{bpm}$ in all patients, and $80.6 \pm 11.0$ or $85.5 \pm 12.3 \mathrm{bpm}$ in patients with and without beta-blocker therapy, respectively. After 4 months of treatment, ivabradine reduced mean $\mathrm{HR}$ by $15.2 \mathrm{bpm}$ to $67.1 \pm 8.4 \mathrm{bpm}$ in the total study cohort. The mean HR dropped by $14.5 \mathrm{bpm}$ to $66.1 \pm 7.9 \mathrm{bpm}$ and by $16.6 \mathrm{bpm}$ to
$69.0 \pm 8.9 \mathrm{bpm}$ in patients with or without existing beta-blocker therapy, respectively $(P<0.001$; Fig. 1$)$. During the course of the study, the proportion of patients with $\mathrm{HR}<70 \mathrm{bpm}$ increased considerably from $12.1 \%$ to $67.5 \%$. Due to their lower baseline $\mathrm{HR}$, patients on beta blocker more often reached $\mathrm{HR}<70 \mathrm{bpm}$ compared to those without beta blocker $(72.3 \%$ vs. 58.8\%). At study end, response rate to ivabradine treatment, defined as $\mathrm{HR}<70 \mathrm{bpm}$ or $\mathrm{HR}$ reduction of $\geq 10 \mathrm{bpm}$, amounted to $87.5 \%$. Only slightly higher response rates were seen in patients with concomitant beta-blocker therapy (and also with higher doses) compared to patients without such treatment $(88.5 \%$ vs. $85.7 \%)$. Treatment response rates were comparable through a wide range of patient subgroups analyzed (Fig. 2).

At baseline, the average number of angina attacks per week was $1.2 \% \pm 1.9$. $49.0 \%$ of all patients suffered from $\geq 1$ angina attack per week. After 4 months, ivabradine led to a decrease of the average number of angina attacks per week to $0.1 \pm 0.6$ (mean difference -1.1 ). Percentage of patients without weekly angina attacks increased from $51.0 \%$ to $92.0 \%$. No marked differences were found for patients with or without concomitant beta-blocker therapy, with a reduction of the average number of angina attacks per week from 1.3 to 0.2 and 1.0 to 0.1 , respectively $(P<0.001$; Fig. 3a, b).

The average baseline consumption of short-acting nitrates per week was $1.5 \pm 2.8$ units. After 4 months of ivabradine therapy, average weekly consumption of short-acting nitrates dropped to $0.2 \pm 1.0$ units (mean difference -1.3 units). Percentage of patients without weekly nitrate use increased from $61.1 \%$ to $92.2 \%$. Comparable results in effect size were observed in patients with or without existing beta-blocker therapy 
Table 1 Baseline characteristics according to beta-blocker therapy

\begin{tabular}{|c|c|c|}
\hline & $\begin{array}{l}\text { Patients } \\
\text { with beta } \\
\text { blocker } \\
(n=798)\end{array}$ & $\begin{array}{l}\text { Patients } \\
\text { without bets } \\
\text { blocker } \\
(n=436)\end{array}$ \\
\hline \multicolumn{3}{|l|}{ Demographic characteristics } \\
\hline Age (years) & $66.2 \pm 10.8$ & $65.9 \pm 11.1$ \\
\hline$\geq 70$ years & $324(41 \%)$ & $179(41 \%)$ \\
\hline$\geq 80$ years & $79(10 \%)$ & $41(9 \%)$ \\
\hline Male sex & $496(62 \%)$ & $219(50 \%)$ \\
\hline $\begin{array}{l}\text { Time since angina } \\
\text { diagnosis (months) }\end{array}$ & $45.7 \pm 47.5$ & $45.4 \pm 48.2$ \\
\hline \multicolumn{3}{|l|}{ Medical history } \\
\hline Previous PCI & $438(55 \%)$ & $146(33 \%)$ \\
\hline Previous CABG & $101(13 \%)$ & $37(8 \%)$ \\
\hline $\begin{array}{l}\text { Previous myocardial } \\
\text { infarction }\end{array}$ & $294(37 \%)$ & $101(23 \%)$ \\
\hline Valvular heart disease & $129(16 \%)$ & $64(15 \%)$ \\
\hline Hypertension & $691(87 \%)$ & $346(79 \%)$ \\
\hline Dyslipidemia & $526(66 \%)$ & $243(56 \%)$ \\
\hline Obesity & $351(44 \%)$ & $160(37 \%)$ \\
\hline Diabetes mellitus & $268(34 \%)$ & $141(32 \%)$ \\
\hline Peripheral artery disease & $76(10 \%)$ & $45(10 \%)$ \\
\hline COPD & $83(10 \%)$ & $130(30 \%)$ \\
\hline Asthma & $24(3 \%)$ & $86(20 \%)$ \\
\hline Nephropathy & $51(6 \%)$ & $31(7 \%)$ \\
\hline \multicolumn{3}{|l|}{ Cardiovascular medication } \\
\hline Beta blockers & $798(100 \%)$ & $0(0 \%)$ \\
\hline ACE inhibitors & $477(60 \%)$ & $216(50 \%)$ \\
\hline $\mathrm{AT}_{1}$ antagonists & $217(27 \%)$ & $130(30 \%)$ \\
\hline $\begin{array}{l}\text { Aldosterone receptor } \\
\text { antagonists }\end{array}$ & $71(9 \%)$ & $19(4 \%)$ \\
\hline Calcium antagonists & $155(19 \%)$ & $109(25 \%)$ \\
\hline Long-acting nitrates & $140(18 \%)$ & $54(12 \%)$ \\
\hline Molsidomine & $76(10 \%)$ & $39(9 \%)$ \\
\hline Ranolazine & $34(4 \%)$ & $14(3 \%)$ \\
\hline
\end{tabular}

Table 1 continued

\begin{tabular}{|c|c|c|}
\hline & $\begin{array}{l}\text { Patients } \\
\text { with beta } \\
\text { blocker } \\
(n=798)\end{array}$ & $\begin{array}{l}\text { Patients } \\
\text { without beta } \\
\text { blocker } \\
(n=436)\end{array}$ \\
\hline Diuretics & $333(42 \%)$ & $163(37 \%)$ \\
\hline Aspirin & $623(78 \%)$ & $296(68 \%)$ \\
\hline $\begin{array}{l}\text { Clopidogrel/prasugrel/ } \\
\text { ticagrelor }\end{array}$ & $134(17 \%)$ & $51(12 \%)$ \\
\hline Statins & $609(76 \%)$ & $252(58 \%)$ \\
\hline $\begin{array}{l}\text { Other lipid-lowering } \\
\text { agents }\end{array}$ & $41(5 \%)$ & $22(5 \%)$ \\
\hline \multicolumn{3}{|l|}{ Clinical findings } \\
\hline Heart rate $(\mathrm{bpm})$ & $80.6 \pm 11.1$ & $85.5 \pm 12.3$ \\
\hline $\begin{array}{l}\text { Weekly number of angina } \\
\text { attacks }\end{array}$ & $1.3 \pm 1.9$ & $1.0 \pm 1.8$ \\
\hline Weekly use of nitrates & $1.8 \pm 3.0$ & $1.1 \pm 2.4$ \\
\hline $\begin{array}{l}\text { Systolic blood pressure } \\
(\mathrm{mm} \mathrm{Hg})\end{array}$ & $135.7 \pm 14.9$ & $137.0 \pm 16.3$ \\
\hline $\begin{array}{l}\text { Diastolic blood pressure } \\
\qquad(\mathrm{mm} \mathrm{Hg})\end{array}$ & $81.1 \pm 9.3$ & $81.5 \pm 9.6$ \\
\hline \multicolumn{3}{|c|}{ Canadian Cardiovascular Society class } \\
\hline Class I & $167(21 \%)$ & $123(28 \%)$ \\
\hline Class II & $428(54 \%)$ & $211(48 \%)$ \\
\hline Class III & $175(22 \%)$ & $79(18 \%)$ \\
\hline Class IV & $9(1 \%)$ & $1(<1 \%)$ \\
\hline
\end{tabular}

Values are presented as patient numbers and percentages or means \pm standard deviations

$A C E$ angiotensin-converting enzyme, $A T_{1}$ angiotensin receptor $1, b p m$ beats per minute, $C A B G$ coronary artery bypass graft, $C O P D$ chronic obstructive pulmonary disease, $P C I$ percutaneous coronary intervention

$(P<0.001$; Fig. 3c), with a drop in average consumption of short-acting nitrates per week from 1.8 to 0.2 and 1.1 to 0.2 units, respectively.

At study entry, $23.8 \%$ of patients were classified CCS grade I, 54.0\% CCS grade II, $21.5 \%$ were in CCS grade III, and $0.6 \%$ in CCS grade IV. A pronounced shift and improvement 
Table 2 Beta-blocker therapy of the study cohort at baseline visit

\begin{tabular}{llllll}
\hline Beta blocker therapy & Metoprolol & Bisoprolol & Nebivolol & Carvedilol & Others $^{\mathbf{b}}$ \\
\hline Patients $(n=798)$ & $362(45 \%)$ & $336(42 \%)$ & $57(7 \%)$ & $32(4 \%)$ & $11(1 \%)$ \\
$\begin{array}{l}\text { Daily dose }(\mathrm{mg} ; n=759) \\
\text { Patient distribution by \% of maximal dose }(n=759)\end{array}$ & $95.1 \pm 48.6$ & $6.1 \pm 3.2$ & $5.0 \pm 1.9$ & $27.3 \pm 15.8$ & - \\
$<50 \%$ & $121(35 \%)$ & $47(14 \%)$ & $11(20 \%)$ & $22(73 \%)$ & - \\
$50-99 \%$ & $174(50 \%)$ & $200(61 \%)$ & $40(71 \%)$ & $8(27 \%)$ & - \\
$\geq 100 \%$ & $52(15 \%)$ & $79(24 \%)$ & $5(9 \%)$ & $0(0 \%)$ & - \\
\hline
\end{tabular}

Values are patient numbers and percentages or means \pm standard deviations

a Defined maximal doses of beta blockers: metoprolol $190 \mathrm{mg} /$ day, bisoprolol and nebivolol $10 \mathrm{mg} / \mathrm{day}$, carvedilol $100 \mathrm{mg} /$ day

b Dose analysis only performed for metoprolol, bisoprolol, nebivolol and carvedilol

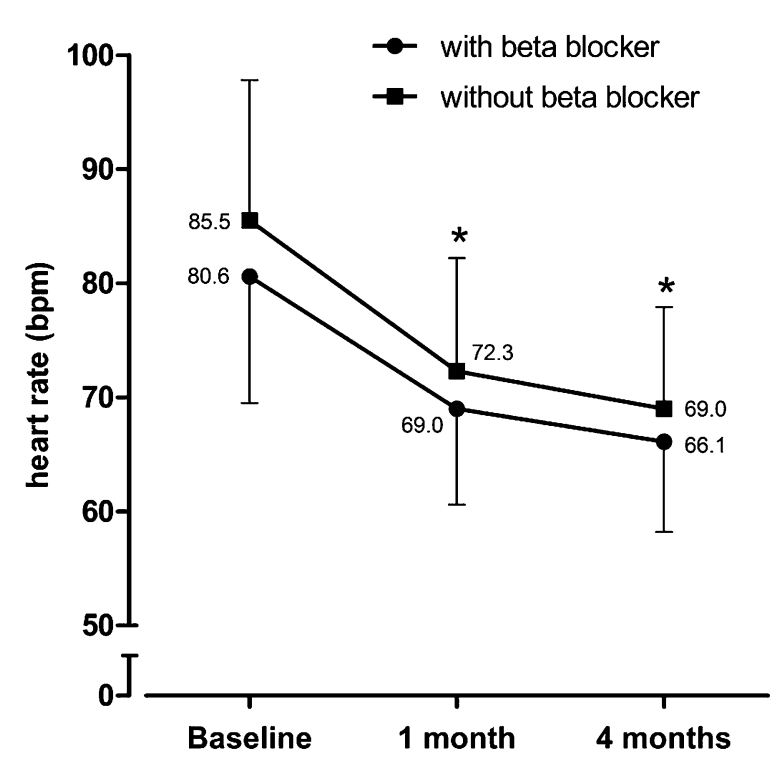

Fig. 1 Reduction in resting heart rate with initiation of ivabradine in patients with stable angina with or without beta-blocker therapy at baseline. ${ }^{*} P<0.001$ (change between baseline and month 1 and baseline and month 4 for both subgroups). $b p m$ beats per minute

in CCS grade distribution towards lower classes was observed. At the end of follow-up, most patients (65.6\%) were classified CCS grade I, $29.9 \%$ were in CCS grade II, $4.6 \%$ in CCS grade III, and none in CCS grade IV $(P<0.001$ for all class changes; Fig. 4). While at baseline, patients on beta blocker were more frequently in severe CCS classes, after four months of ivabradine therapy, no clear differences were documented for patients with or without concomitant beta-blocker intake. Symptomatic improvement and CCS classification shifts were generally comparable among the specified patient subgroups and irrespective of a concomitant beta-blocker therapy or the applied beta-blocker dose $(<50 \%, 50-99 \%$, or $\geq 100 \%$ of maximal dose). For all effectiveness parameters, most of the beneficial effects associated with ivabradine therapy were already observed in month 1 with a further increase in month 4 .

Overall, during the course of the study no relevant changes in beta-blocker therapy or dosage, or that of other cardiovascular and anti-anginal medications, were documented. Adherence to treatment with ivabradine was quite high, with $4.4 \%$ of patients discontinuing treatment during the study period.

\section{Tolerability}

ADR were reported for $2.2 \%(n=28)$ of patients (mostly bradycardia $0.4 \%$, palpitations $0.2 \%$, photopsia 0.2\%). Serious ADRs (SADRs) occurred in $0.4 \%(n=5)$ of patients, e.g., bradycardia and atrial fibrillation. There were 


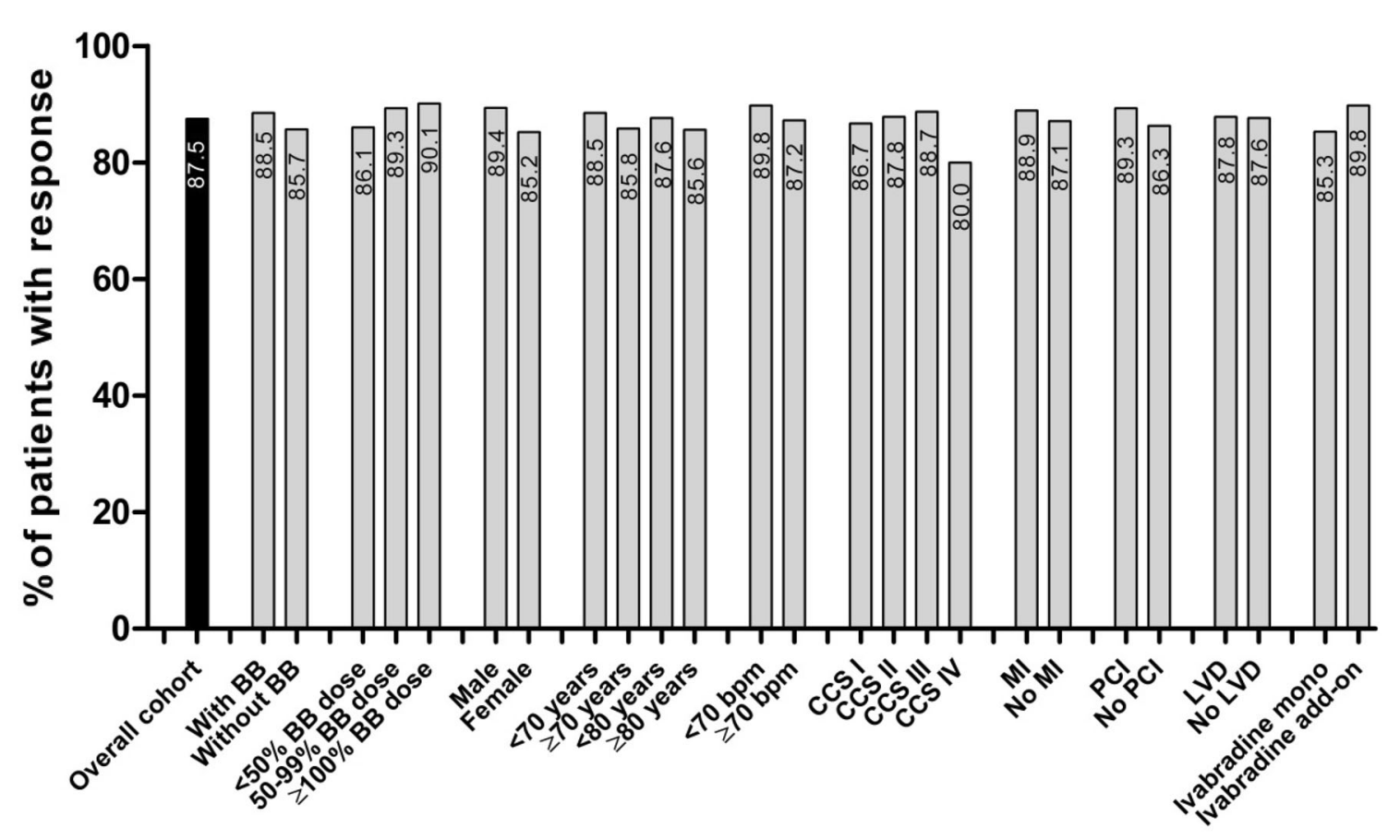

Fig. 2 Treatment response in various subgroups after 4 months of ivabradine therapy. "Response" defined as achieving a heart rate $<70 \mathrm{bpm}$ or a heart rate reduction of $\geq 10 \mathrm{bpm}$ after 4 months. $B B$ beta blocker, $b p m$ beats

no SADRs resulting in MI or death. No unexpected safety signals have been reported. In addition, there was no relevant difference in ADR/SADR incidence rates or their profile between patients with or without existing beta-blocker therapy (Table 3). Finally, the effectiveness of ivabradine treatment was rated by the treating physicians as "very good" and "good" for $71.3 \%$ and $26.3 \%$ of patients, and tolerability for $76.5 \%$ and $22.4 \%$, respectively. Both in terms of effectiveness and tolerability rating, no pronounced effect of concomitant beta-blocker therapy was documented.

\section{DISCUSSION}

The main finding of our study is that the selective $I_{\mathrm{f}}$ inhibitor ivabradine is effective and safe in a broad spectrum of patients with per minute, CCS Canadian Cardiovascular Society, LVD left ventricular dysfunction, $M I$ myocardial infarction, $P C I$ percutaneous coronary intervention

Fig. 3 Change in angina frequency (a), mean number of angina attacks (b) and frequency of nitrate uses (c) per week in patients with or without beta-blocker therapy at baseline. ${ }^{*} P<0.001$ (change between baseline and month 1 and/or baseline and month 4 for both subgroups)

stable CAD with or without concomitant beta-blocker therapy, showing consistently high treatment response rates regarding $\mathrm{HR}$ reduction. To our knowledge, the present study is the first to analyze response to ivabradine treatment in a wide range of subgroups in clinical practice.

For the use of ivabradine without existing beta-blocker therapy, symptomatic effects in our study are in line with results of various clinical trials $[23,24]$. In the INITIATIVE study, an equivalent symptomatic efficacy of ivabradine and the beta-blocker atenolol was proven [23]. Our findings mirror as well the 

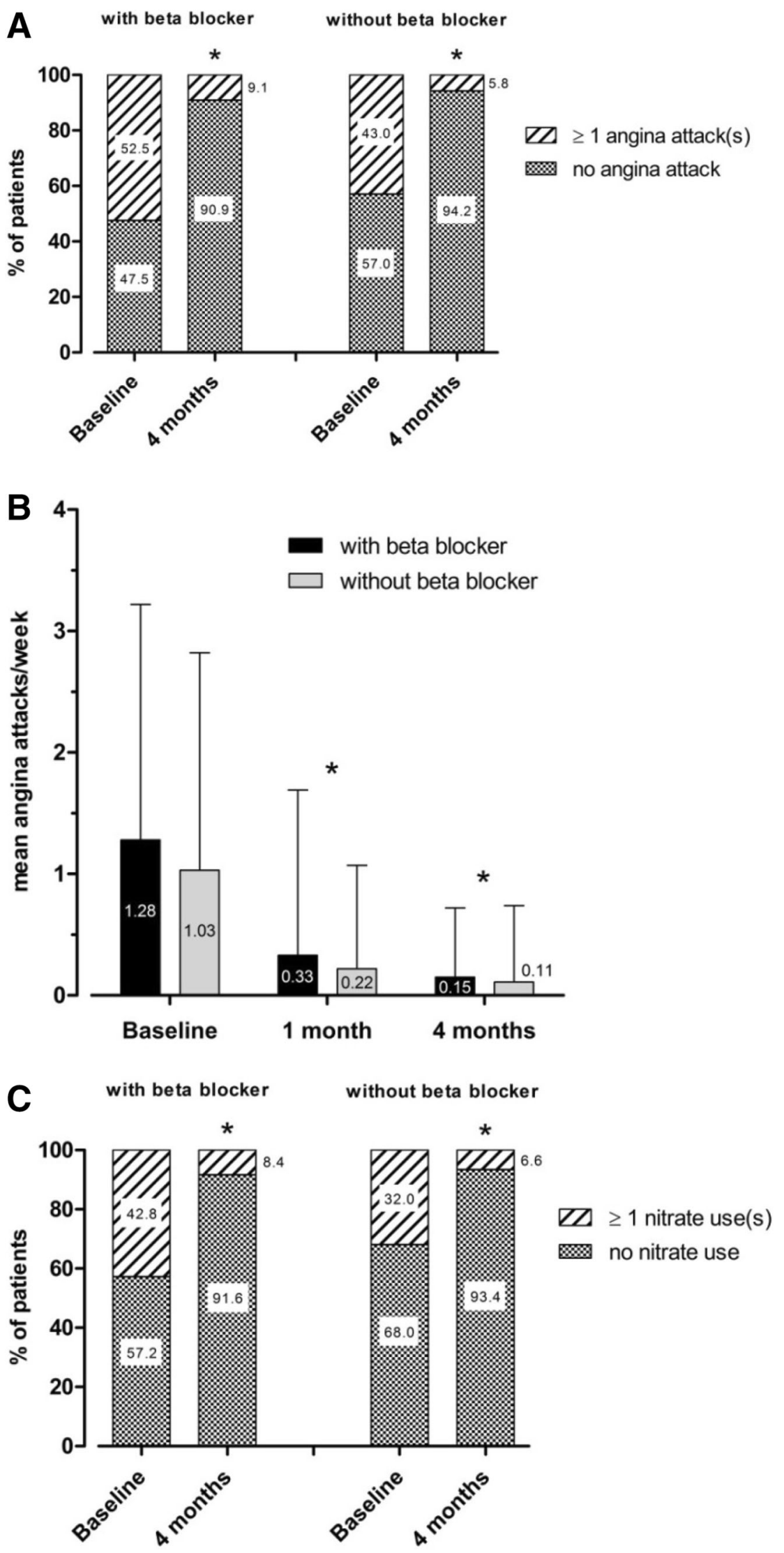


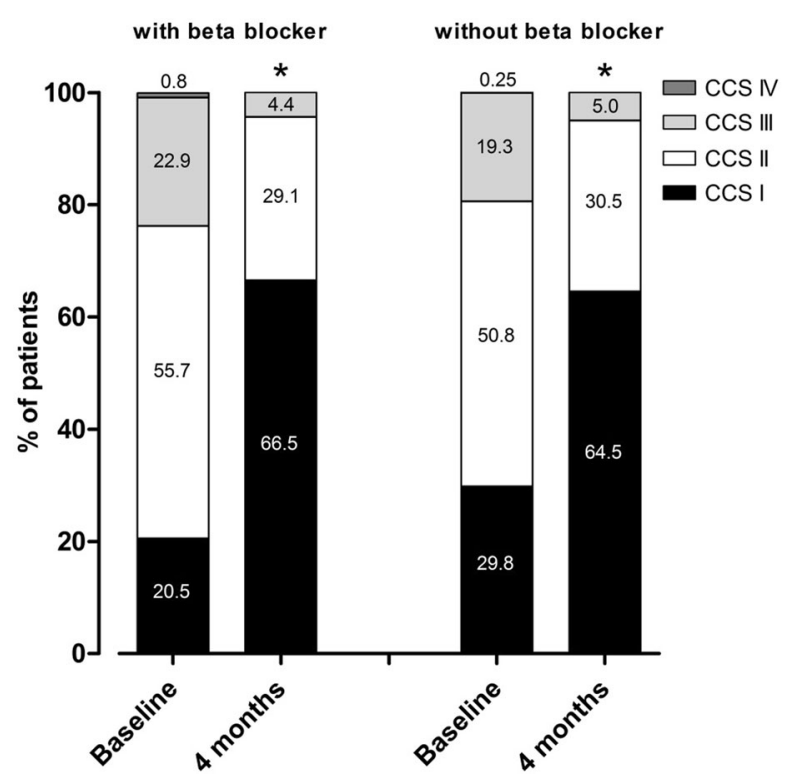

Fig. 4 Change in severity of angina from baseline to 4 months, according to CCS class, in patients with or without beta-blocker therapy at baseline. ${ }^{*} P<0.001$ (change between baseline and month 4 for both subgroups). CCS Canadian Cardiovascular Society

symptomatic effectiveness and safety profile of ivabradine in combination with beta blocker previously demonstrated in the ASSOCIATE trial [25], and in two non-interventional studies [27, 28]. Taken together, all these previous studies concluded that ivabradine as either antianginal monotherapy or in combination with beta blocker was effective and well tolerated, not only in selected patient populations but also in daily clinical practice.

In our study, a typical mixed population of patients with stable CAD in the outpatient setting with angina symptoms and including participants with or without LVD was assessed. To further strengthen the available data on HR reduction, improvement of angina symptoms and tolerability with ivabradine as monotherapy or combined with beta blocker, we decided to design a non-interventional study as this might result in a more realistic picture of everyday use of the drug in, e.g.,
Table 3 Most frequently reported adverse drug reactions, according to beta-blocker therapy, classified using MedDRA (medical dictionary for regulatory activities)

\begin{tabular}{lll}
\hline $\begin{array}{l}\text { Adverse drug } \\
\text { reaction }\end{array}$ & $\begin{array}{l}\text { Patients with } \\
\text { beta blocker } \\
(\boldsymbol{n}=798)\end{array}$ & $\begin{array}{l}\text { Patients } \\
\text { without beta } \\
\text { blocker } \\
(\boldsymbol{n}=436)\end{array}$ \\
\hline $\begin{array}{l}\text { All adverse drug } \\
\text { reactions }\end{array}$ & $18(2.3 \%)$ & $10(2.3 \%)$ \\
Bradycardia & $3(0.4 \%)$ & $2(0.5 \%)$ \\
$\begin{array}{l}\text { Dizziness/syncope } \\
\text { Palpitations }\end{array}$ & $2(0.3 \%)$ & $1(0.2 \%)$ \\
Photopsia & $2(0.3 \%)$ & $1(0.2 \%)$ \\
$\quad$ phosphenes) & $2(0.3 \%)$ & $1(0.2 \%)$ \\
Atrial fibrillation & $1(0.1 \%)$ & $1(0.2 \%)$ \\
\hline
\end{tabular}

Values are patient numbers and percentages

elderly patients with comorbidities, which are usually not sufficiently represented in controlled clinical trials.

Adding ivabradine to the treatment plan led to a further substantial reduction in resting $\mathrm{HR}$ by $15.2 \mathrm{bpm}$ without relevant differences between patients treated with beta blocker or not. Taking into account a slightly lower baseline HR in the two-thirds of patients on beta blockers compared to patients without beta blocker (80.6 vs. $85.5 \mathrm{bpm}), 4$ months of ivabradine therapy allowed for a better HR control in both subgroups with only small between-group variation. A similar observation was made in terms of treatment response (HR $<70 \mathrm{bpm}$ or $\mathrm{HR}$ reduction of $\geq 10 \mathrm{bpm}$ at month 4) with an only slightly higher success rate for patients treated with both ivabradine and beta blocker. These results are in good agreement with findings from a large observational study, where a comparable reduction of $\mathrm{HR}$ in participants with or without concomitant beta-blocker therapy was 
found [26], although the proportion of patients treated with beta blockers was considerably lower in that cohort. HR response rates and symptomatic effects were comparable across all analyzed subgroups.

Correspondingly, after 4 months of ivabradine therapy both the weekly number of angina attacks and consumption of short-acting nitrates declined substantially. At study end, approximately $90 \%$ of patients were free of angina symptoms and without need to use short-acting nitrates. These observations were accompanied by a pronounced shift in CCS grade distribution towards lower classes. Despite beta-blocker patients being more symptomatic at baseline, probably reflecting the fact that sicker patients were more likely to receive beta blockers, the treatment effect of ivabradine was consistent and comparable in patients with or without beta-blocker therapy after 4 months. At the end of follow-up, the percentage of patients in CCS grade I almost tripled irrespective of concomitant beta-blocker therapy. Although QoL was not specifically addressed in our study, a strong correlation between CCS classification and health-related QoL questionnaires like the EQ-5D is well established [29]. Given this association, an additional benefit of ivabradine therapy on QoL has been demonstrated in patients on beta blockers in the ADDITIONS study (Controlled-trials.com identifier: ISRCTN532 33058) [28] and can also be assumed for the present study cohort on basis of the improvement in CCS grade distribution after 4 months of treatment.

Overall, the magnitude of HR reduction, decline of angina symptoms, nitrate consumption, and improvement in CCS class with ivabradine over 4 months was comparable to previous observational studies [26, 28]. Moreover, a small subgroup analysis of an observational study allowing a comparison of ivabradine patients with and without existing beta-blocker therapy revealed no clear influence of beta-blocker therapy on the effectiveness or tolerability of ivabradine in "real-life" patients with stable AP [27], emphasizing the findings of our study. In addition, no relevant differences between HR reduction or its effects on angina symptoms, nitrate use or CCS class improvement were revealed between patients taking $<50 \%$, $50-99 \%$, or $100 \%$ of the maximal beta-blocker dose. In support of our results, reaching maximal approved beta-blocker doses failed to show additional positive effects in combination with ivabradine in patients with stable AP [30] and CHF [31] compared to lower beta-blocker doses.

In our unselected patient population the effect on HR was more pronounced than in the BEAUTIFUL or SHIFT study (Controlledtrials.com identifier: ISRCTN70429960) $[17,32]$, which might be explained by the higher baseline HR despite beta-blocker treatment in the majority of patients. Greater HR reduction with ivabradine was in good agreement to that seen in "real-life" patients in other non-interventional studies $[26,28]$ and can be explained with the pharmacological properties of ivabradine, for which the magnitude of the HR-reducing effect is considered "use-dependent" and strongly correlates to baseline HR $[13,33]$. High HR at baseline may also reflect physicians' perception that ivabradine is especially indicated and useful in patients with considerably high resting HR. The treatment decision should rather be in line with results from studies like BEAUTIFUL [17, 18] or SHIFT [32], in which patients with an initial $\mathrm{HR} \geq 70 \mathrm{bpm}$ showed pronounced benefit on certain outcome endpoints. The mean HR achieved in our study was $67.1 \mathrm{bpm}$, which is still above the 
resting HR $(<60 \mathrm{bpm})$ recommended in international guidelines for patients with stable CAD [10, 11]. This might also be explained by the relatively low dose of ivabradine with a mean daily dose of $11.0 \mathrm{mg}$ at last visit, compared to the approved maintenance dose of $15 \mathrm{mg} /$ day. Up-titration to the full dose might have further increased the therapeutic effects of ivabradine.

In good agreement with recent registries and surveys [21, 22], beta blockers in our study were mostly not at maximal dose due to either side effects (mostly tiredness, fatigue, erectile dysfunction, hypotension) or existing comorbidities (chronic obstructive pulmonary disease, asthma, conduction disturbances, psoriasis). As up-titration was not successful in these symptomatic patients with persistently elevated HR due to the mentioned obstacles, alternative anti-anginal treatment needed to be considered. The current results show that combining beta blocker with ivabradine appears to be a valuable option in patients who do not tolerate high-dose beta-blocker therapy or those with insufficient reduction of HR or with persisting angina symptoms. Moreover, there are convincing study data showing that adding ivabradine to beta blockers seems to be more effective than up-titration of beta blockers in patients with stable AP [34].

Combined ivabradine and beta-blocker therapy was well tolerated without any relevant differences compared to patients receiving ivabradine without beta blocker. The rate of ADR is in good agreement with results from other non-interventional studies [26, 28, 31], but is lower than in randomized, controlled trials $[17,32]$, which might also be explained by higher HR at inclusion in the present study. In particular, the SADR rate was low $(0.4 \%)$, and altogether only $0.4 \%$ of the patients experienced bradycardia. Of special interest is the sharp contrast to the recent findings of the large randomized, controlled SIGNIFY study, where ivabradine was applied "off-label" in a higher than authorized starting $(2 \times 7.5 \mathrm{mg}$ per day $)$ and maintenance dose (up to $2 \times 10 \mathrm{mg}$ per day), resulting in excess bradycardia and a small but significant increase of primary endpoint events in a subgroup of patients with limiting angina [19]. Concomitant therapy with the HR-lowering calcium antagonists verapamil and diltiazem $(4 \%$ of patients in the angina subgroup) was considered as another important risk factor in this trial. As a result of a thorough reviewing process of the SIGNIFY data by the European Medicines Agency (EMA), combining ivabradine with verapamil or diltiazem is now contraindicated. Although $8 \%$ of our patients were on one of these drugs, no apparent safety signals could be detected with ivabradine given within the limits of its usual and approved dosing regimen.

Taken together, the results from RESPONSI $I_{\mathrm{f}} \mathrm{VE}$ add to the current evidence showing a marked symptomatic improvement in patients with stable AP in everyday practice with ivabradine given either as sole antianginal therapy or in combination with beta blocker. The effect size and tolerability were independent of concomitant beta-blocker therapy. It should be noted in this context that apart from HR-dependent effects there is also good evidence for pleiotropic actions of ivabradine, which are independent from HR reduction. Mechanisms for example involve attenuated formation of reactive oxygen species in cardiomyocyte mitochondria $[35,36]$. Such results distinguish ivabradine from other currently used anti-anginal medication, like beta blockers, calcium antagonists or nitrates and may have contributed to the effects seen in RESPONSI $\mathrm{fEE}$. 


\section{Study Limitations}

One important limitation of this trial is its open-label, observational, non-interventional design without placebo group, which may lead to an overestimation of treatment effects. The efficacy of ivabradine with or without beta blocker use has been consistently proven in controlled clinical trials with patients with chronic stable AP [23-25]. Moreover, our open study design allows evaluation of treatment effects under conditions of routine clinical practice, while in controlled studies strict inclusion criteria usually restrict access of broader patient populations with multiple comorbidities and risk factors. Another limitation is the short study duration of 4 months, which is nevertheless sufficient to evaluate symptom reduction in patients with $\mathrm{AP}$, as demonstrated in other controlled and "real-life" studies [25, 26, 28]. High resting HR at baseline can also lead to an overestimation of the treatment benefit, as ivabradine effects are more pronounced in patients with high HR due to its use-dependent mechanism of action $[13,33]$. But with less than a quarter of patients being up-titrated to the target dose of ivabradine beneficial effects may also be undervalued.

Due to the non-interventional design, an underestimation of potentially ivabradinerelated adverse events cannot be fully excluded, as they were assessed only in the form of an open evaluation at each visit. But taking into account favorable safety results from clinical trials, when used according to the approved dosing regimen, ivabradine alone or in combination with beta-blocker therapy and other frequently prescribed drugs appears to be well tolerated in patients with chronic stable AP.

\section{CONCLUSIONS}

In this prospective study over a four-month period in daily clinical practice, ivabradine effectively reduced HR, angina symptoms and nitrate consumption in a cohort of patients with chronic stable AP with or without existing beta-blocker therapy. Moreover, ivabradine improved CCS symptom scores and achieved high treatment response rates in this mixed population with cardiovascular comorbidities. Treatment effects of ivabradine were comparable in patients with or without beta-blocker use and in various other subgroups. Ivabradine therapy was associated with a good general tolerability profile. In line with current guideline recommendations, the results of our study emphasize the potential for better HR and symptom control with ivabradine in patients with chronic stable AP, irrespective of concomitant beta-blocker treatment.

\section{ACKNOWLEDGMENTS}

Sponsorship, article processing charges, and the open access fee for this study were funded by Servier Deutschland GmbH, Munich, Germany. All named authors meet the International Committee of Medical Journal Editors (ICMJE) criteria for authorship for this manuscript, take responsibility for the integrity of the work as a whole, and have given final approval for the version to be published. The authors would like to thank all investigators for their contributions to the study, Dr. Irina Elyubaeva for helpful discussions and Dr. Michael Lohmann for assistance in the preparation of the manuscript. Subsets of these data have been presented as posters at the fall meeting of the German Cardiac Society in 2014 and the annual 
congress of the German Cardiac Society in 2015.

\section{Disclosures. Stefan Perings received} honoraria from Servier as scientific coordinator of this study. Georg Stöckl is an employee of Servier Deutschland GmbH, Munich (Medical Affairs Department). Malte Kelm reports no conflicts of interest.

Compliance with Ethics Guidelines. All procedures followed were in accordance with the ethical standards of the responsible committee on human experimentation (institutional and national) and with the Helsinki Declaration of 1975, as revised in 2000 and 2008. Informed consent was obtained from all patients for being included in the study.

Open Access. This article is distributed under the terms of the Creative Commons Attribution-NonCommercial 4.0 International License (http://creativecommons.org/licenses/ by-nc/4.0/), which permits any noncommercial use, distribution, and reproduction in any medium, provided you give appropriate credit to the original author(s) and the source, provide a link to the Creative Commons license, and indicate if changes were made.

\section{REFERENCES}

1. Heusch G. Heart rate in the pathophysiology of coronary blood flow and myocardial ischaemia: benefit from selective bradycardic agents. $\mathrm{Br} \mathrm{J}$ Pharmacol. 2008;153(8):1589-601.

2. Custodis F, Schirmer SH, Baumhäkel M, et al. Vascular pathophysiology in response to increased heart rate. J Am Coll Cardiol. 2010;56(24):1973-83.

3. Camici PG, Gloekler S, Levy BI, et al. Ivabradine in chronic stable angina: effects by and beyond heart rate reduction. Int J Cardiol. 2016;215:1-6.
4. Fox K, Borer JS, Camm AJ, et al. Resting heart rate in cardiovascular disease. J Am Coll Cardiol. 2007;50(9):823-30.

5. Reil JC, Custodis F, Swedberg K, et al. Heart rate reduction in cardiovascular disease and therapy. Clin Res Cardiol. 2010;100(1):11-9.

6. Fox K, Ford I, Steg PG, et al. Heart rate as a prognostic risk factor in patients with coronary artery disease and left-ventricular systolic dysfunction (BEAUTIFUL): a subgroup analysis of a randomised controlled trial. Lancet. 2008;372(9641):817-21.

7. Böhm M, Swedberg K, Komajda M, et al. Heart rate as a risk factor in chronic heart failure (SHIFT): the association between heart rate and outcomes in a randomised placebo-controlled trial. Lancet. 2010;376(9744):886-94.

8. Kannel WB, Kannel C, Paffenbarger RS, et al. Heart rate and cardiovascular mortality: the Framingham Study. Am Heart J. 1987;113(6):1489-94.

9. Custodis F, Roggenbuck U, Lehmann N, et al. Resting heart rate is an independent predictor of all-cause mortality in the middle aged general population. Clin Res Cardiol. 2016;105(7):601-12.

10. Fihn SD, Gardin JM, Abrams J, et al. ACCF/AHA/ ACP/AATS/PCNA/SCAI/STS guideline for the diagnosis and management of patients with stable ischemic heart disease: a report of the American College of Cardiology Foundation/ American Heart Association task force on practice guidelines, and the American College of Physicians, American Association for Thoracic Surgery, Preventive Cardiovascular Nurses Association, Society for Cardiovascular Angiography and Interventions, and Society of Thoracic Surgeons. J Am Coll Cardiol. 2012;60(24):e44-164.

11. Montalescot G, Sechtem U, Achenbach S, et al. 2013 ESC guidelines on the management of stable coronary artery disease: the task force on the management of stable coronary artery disease of the European Society of Cardiology. Eur Heart J. 2013;34(38):2949-3003.

12. McMurray J, Adamopoulos S, Anker SD, et al. ESC guidelines for the diagnosis and treatment of acute and chronic heart failure 2012. Eur Heart J. 2012;33(14):1787-847.

13. Di Francesco D, Camm AJ. Heart rate lowering by specific and selective $I_{\mathrm{f}}$ current inhibition with ivabradine: a new therapeutic perspective in cardiovascular disease. Drugs. 2004;64(16): 1757-65. 
14. Andersson C, Shilane D, Go AS, et al. $\beta$-blocker therapy and cardiac events among patients with newly diagnosed coronary heart disease. J Am Coll Cardiol. 2014;64(3):247-52.

15. Bangalore S, Bhatt DL, Steg PG, et al. $\beta$-blockers and cardiovascular events in patients with and without myocardial infarction: post hoc analysis from the CHARISMA trial. Circ Cardiovasc Qual Outcomes. 2014;7(6):872-81.

16. Bangalore S, Makani H, Radford M, et al. Clinical outcomes with $\beta$-blockers for myocardial infarction: a meta-analysis of randomized trials. Am J Med. 2014;127(10):939-53.

17. Fox K, Ford I, Steg PG, et al. Ivabradine for patients with stable coronary artery disease and left-ventricular systolic dysfunction (BEAUTIFUL): a randomised, double-blind, placebo-controlled trial. Lancet. 2008;372(9641):807-16.

18. Fox K, Ford I, Steg PG, et al. Relationship between ivabradine treatment and cardiovascular outcomes in patients with stable coronary artery disease and left ventricular systolic dysfunction with limiting angina: a subgroup analysis of the randomized, controlled BEAUTIFUL trial. Eur Heart J. 2009;30(19):2337-45.

19. Fox K, Ford I, Steg PG, et al. Ivabradine in stable coronary artery disease without clinical heart failure. N Engl J Med. 2014;371(12):1091-9.

20. Bauters C, Deneve M, Tricot O, et al. Prognosis of patients with stable coronary artery disease (from the CORONOR study). Am J Cardiol. 2014;113(7):1142-50.

21. Daly CA, Clemens F, Sendon JL, et al. Inadequate control of heart rate in patients with stable angina: results from the European heart survey. Postgrad Med J. 1014;2010(86):212-7.

22. Steg PG, Ferrari R, Ford I, et al. Heart rate and use of beta blockers in stable outpatients with coronary artery disease. PLoS One. 2012;7(5):e36284.

23. Tardif JC, Ford I, Tendera M, et al. Efficacy of ivabradine, a new selective I(f) inhibitor, compared with atenolol in patients with chronic stable angina. Eur Heart J. 2005;26(23):2529-36.

24. Ruzyllo W, Tendera M, Ford I, Fox KM. Antianginal efficacy and safety of ivabradine compared with amlodipine in patients with stable effort angina pectoris: a 3-month randomized, double-blind, multicenter, non-inferiority study. Drugs. 2007;67(3):393-405.

25. Tardif JC, Ponikowski P, Kahan T, et al. Efficacy of the $I_{\mathrm{f}}$ current inhibitor ivabradine in patients with chronic stable angina receiving beta blocker therapy: a 4 month, randomized, placebo-controlled trial. Eur Heart J. 2009;30(5):540-8.

26. Köster R, Kähler J, Meinertz T. Treatment of stable angina pectoris by ivabradine in every day practice: the REDUCTION study. Am Heart J. 2009;158(4):e51-7.

27. Köster R, Kähler J, Ebelt $\mathrm{H}$, et al. Ivabradine in combination with beta blocker therapy for the treatment of stable angina pectoris in every day clinical practice. Clin Res Cardiol. 2010;99(10):665-72.

28. Werdan K, Ebelt H, Nuding S, et al. Ivabradine in combination with beta blocker improves symptoms and quality of life in patients with stable angina pectoris: results from the ADDITIONS study. Clin Res Cardiol. 2012;101(5):365-73.

29. Dyer MT, Goldsmith KA, Sharples LS, Buxton MJ. A review of health utilities using the EQ-5D in studies of cardiovascular disease. Health Qual Life Outcomes. 2010;8:13.

30. Werdan K, Ebelt H, Stöckl G, et al. Long-term therapy with ivabradine in combination with beta blockers in patients with stable angina pectoris and effect of beta blocker background dose: results from the ADDITIONS 1-year follow-up. Eur Heart J. 2013;34(Abstract Suppl):175-6.

31. Zugck C, Martinka P, Stöckl G. Ivabradine treatment in a chronic heart failure patient cohort: symptom reduction and improvement in quality of life in clinical practice. Adv Ther. 2014;31(9):961-74.

32. Swedberg K, Komajda M, Böhm M, et al. Ivabradine and outcomes in chronic heart failure (SHIFT): a randomised placebo-controlled study. Lancet. 2010;376(9744):875-85.

33. Savelieva I, Borer JS, Camm AJ. Low incidence of significant bradycardia during therapy with an $I_{\mathrm{f}}$ current inhibitor ivabradine: heart rate reduction depends on baseline heart rate. J Am Coll Cardiol. 2007;49(9 Suppl A):1007.

34. Amosova E, Andrejev E, Zaderey I, et al. Efficacy of ivabradine in combination with beta blocker versus uptitration of beta blocker in patients with stable angina. Cardiovasc Drugs Ther. 2011;25(6):531-7.

35. Heusch G, Kleinbongard P. Ivabradine: cardioprotection by and beyond heart rate reduction. Drugs. 2016;76(7):733-40.

36. Kleinbongard $\mathrm{P}$, Gedik $\mathrm{N}$, Witting $\mathrm{P}$, et al. Pleiotropic, heart rate-independent cardioprotection by ivabradine. $\mathrm{Br} \mathrm{J}$ Pharmacol. 2015;172(17):4380-90. 